\title{
Incidence of injuries among amateur badminton players
}

\section{A cross-sectional study}

\author{
Ana Marchena-Rodriguez ${ }^{\mathrm{a}}$, Gabriel Gijon-Nogueron, PhD ${ }^{\mathrm{b}}$, David Cabello-Manrique,, \\ Ana Belen Ortega-Avila, $\mathrm{PhD}^{\mathrm{a}}$
}

\begin{abstract}
The main aims of this study were, firstly, to investigate the frequency, location, and severity of injuries in amateur badminton players, and then to determine risk factors that may be associated with a higher incidence of injuries.

A cross-sectional study, composed of 150 players drawn from the 2018 BWF European Senior Championships, was analyzed. The definitions and types of injury included in the study are based on those published in previous epidemiology studies.

Among the 150 players analyzed, 221 injuries were observed, of which the highest proportion $(40.3 \%, n=89)$ affected the lower limb. Of these $22.44 \%$ were to the knee and $18.3 \%$ to the leg. In the upper limb, the shoulder was most frequently affected (11.8\%). The mean rate of injuries per 1000 hours of play was 0.134 (standard deviation [SD]: 0.1), with 0.138 (SD: 0.1 ) among the male players and 0.131 (SD: 0.08) among the female players $(P=.981: F=0.001)$. The average duration of the injuries suffered exceeded 28 days in $34.5 \%$ of the cases.

The incidence of injury varied according to sex and age. Most injuries affected the muscles, especially those of the knee (in the lower limbs) and the shoulder (in the upper limbs).
\end{abstract}

Abbreviations: $\mathrm{BIM}=$ body index mass, $\mathrm{IR}=$ injury rate, $\mathrm{SD}=$ standard deviation.

Keywords: badminton, epidemiology, injury, player

\section{Introduction}

Badminton is an individual, non-contact sport requiring jumps, lunges, quick changes of direction, and rapid arm movements from a wide variety of body positions. The physical demands of badminton suggest that acute injuries to the limbs may frequently occur. ${ }^{[1]}$ However, overuse injuries may also affect the back, shoulder, lower leg, and knee. ${ }^{[2,3]}$

\section{Editor: Undurti N. Das.}

This study did not receive any funding.

Ethical approval: The study protocol was approved by the Medical Research Ethics Committee of the University of Malaga (CEUMA 67-2015-H).

The authors have no conflicts of interest to disclose.

${ }^{a}$ Department of Nursing and Podiatry, ${ }^{b}$ Department of Nursing and Podiatry, Instituto de Investigación Biomédica de Málaga (IBIMA), Universidad de Málaga, ${ }^{c}$ Physical Education and Sports Department, Faculty of Sport Sciences, iMUDS University of Granada, Granada, Spain.

* Correspondence: David Cabello-Manrique, Physical Education and Sports Department, Faculty of Sport Sciences, iMUDS - University of Granada, Granada, Spain (e-mail: dcabello@ugr.es).

Copyright $\odot 2020$ the Author(s). Published by Wolters Kluwer Health, Inc. This is an open access article distributed under the terms of the Creative Commons Attribution-Non Commercial License 4.0 (CCBY-NC), where it is permissible to download, share, remix, transform, and buildup the work provided it is properly cited. The work cannot be used commercially without permission from the journal.

How to cite this article: Marchena-Rodriguez A, Gijon-Nogueron G, CabelloManrique $D$, Ortega-Avila $A B$. Incidence of injuries among amateur badminton players: A cross sectional study. Medicine 2020;99:18(e19785).

Received: 13 October 2019 / Received in final form: 24 December 2019 /

Accepted: 27 February 2020

http://dx.doi.org/10.1097/MD.0000000000019785
The lower extremities must sustain a high level of stress in the demanding movements of badminton, which may result in discomfort and injury. ${ }^{[4]}$ In the upper limb, the joint bearing the greatest load is the shoulder. The movements are usually abduction/external rotation with rapid movements of the arm that impose severe loads on the joints and can lead to shoulder, elbow, and wrist injuries. ${ }^{[3]}$

No recent studies have been undertaken to obtain epidemiological data on badminton injuries. However, according to the limited information available, these injuries are often severe but of relatively low frequency. It has been estimated that badminton injuries account for $1 \%$ to $5 \%$ of all sports injuries. ${ }^{[3,5,6]}$ In epidemiology studies regarding badminton, Jorgensen and Winge $^{[7]}$ reported an incidence of 2.9 injuries per 1000 playing hours, Yung et al ${ }^{[1]}$ measured a rate of 5.04 injuries per 1000 playing hours among elite players and Goh et $\mathrm{al}^{[8]}$ reported rates between 0.9 and 5.1 injuries per 1000 playing hours. However, injuries are still common as players need to generate enormous power even while in disadvantaged postural positions.

In general, men are more frequently injured than female players. ${ }^{[9]}$ However, when the higher rate of participation of male players is taken into consideration, the incidence does not vary greatly between the sexes. ${ }^{[10]}$ However, there was a significant increase in injury rate (IR) with age and significantly higher IRs in female players than in male players in all age groups. The mechanical load during matches increases with the level of competition, which increases with age; this might explain the ageassociated increase in IR. The differences in IR by sex may partially be explained by differences in basic physical strength. ${ }^{[11]}$ The injuries suffered are mainly to the muscles, and the most frequent location is the lower limb. ${ }^{[7]}$ Badminton players must react to the moving shuttlecock and adjust their body position 
rapidly and continuously throughout the game. ${ }^{[12]}$ They must maintain their center of gravity within the base of support while performing very rapid and asymmetrical upper limb movements. ${ }^{[13]}$ Therefore, superior body balance is crucial for badminton skill advancement, sports performance, and injury prevention. ${ }^{[1]}$ Amateur badminton players have superior performance accuracy in badminton serving, but not static and dynamic balance performance, agility, or eye-hand coordination, relative to healthy active controls. ${ }^{[14]}$ Accordingly, the main aim of our study was to investigate the frequency, location, and severity of injuries suffered by amateur badminton players.

\section{Method}

\subsection{Design}

A cross-sectional study was drawn from the 2018 BWF European Senior Championships.

\subsection{Subjects}

A convenience sample was obtained from 150 players. The participants in this study were drawn from players at the BWF European Senior Championships held in Guadalajara (Spain) in September 2018. The inclusion criteria were: $>18$ years of age, were able to follow the study instructions and informed consent was obtained in every case. The exclusion criteria were lowerlimb surgery and neurological injury.

\subsection{Data collection and definition of injuries}

The study data were compiled prospectively by the interviewing medical team. In every case, the complementary information necessary for diagnosis (magnetic resonance imaging, $\mathrm{x}$-ray, or ultrasound scan) was obtained.

The definition of each injury was based on the criteria adopted in previous research. ${ }^{[8,9]}$ Any pain and/or discomfort reported by players to the medical staff and receiving medical attention was considered to be an injury.

Injury severity was categorized as slight (no time lost), minimal (1-3 days lost), mild (4-7 days lost), moderate (8-28 days lost), or severe ( $>28$ days lost). Injuries were classified according to the following locations: foot/toe, ankle, lower leg-Achilles tendon, knee, thigh, hip, trunk, neck, shoulder, arm, elbow, wrist, hand or fingers. The types of injury were classed as tendinopathy, muscular, fracture, ligament or other.

The players' exposure time was classed as match exposure, training exposure, and total exposure, measured in hours and compiled by the respective trainers. Throughout the study period, the playing surface was used was synthetic.

The study data were entered into the dataset by 2 research assistants, working independently and blinded to the purposes of this study. Therefore, all data were double-checked before the statistical analysis.

\subsection{Data analysis}

The results obtained are reported as means and standard deviations and, by type of statistics, as frequencies, crosstabulations, and descriptive. The incidence of injuries is reported as injuries per 1000 playing hours. The normality of the distributions was confirmed by the Kolmogorov-Smirnov test. Bivariate analyses were carried out by the chi square method and through a general linear model, and sphericity was evaluated by Mauchly test. Finally, a multivariate linear regression model was obtained to evaluate predictors of injury. The significance level was set at $P<.05$. All statistical analyses were conducted using SPSS v. 24.0 (SPSS Inc., Chicago, IL).

\subsection{Ethical issues}

This study was carried out in full accordance with the Declaration of Helsinki on ethical principles for medical research involving human subjects and was approved by the Ethics Committee of the University of Malaga (CEUMA 67/2015H) (Spain).

\section{Results}

This sample produced 322 data records generated by 150 players, of whom $104(69.33 \%)$ were men. The mean age of the cohort was 50.18 years (SD: 10.72) and the mean body mass index (BMI) was 25.56 (SD: 3.36) (Table 1).

The mean duration of playing experience was 27.20 years (14.4) and $91.3 \%$ of the players were right-handed. $61.3 \%$ played singles and doubles matches and only $5.3 \%$ played single matches. In our sample, injuries were suffered by male and female players in a ratio of 2.07 to 1.99 respectively $(P=.130: F=2.31)$. The mean rate of injuries, for all players, per 1000 hours of training was 0.134 (SD: 0.1), and the corresponding figures for male and female players were 0.138 (SD: 0.1$)$ and 0.131 (SD: $0.08)$, respectively $(P=.981: F=0.001)$.

In total, 322 injuries were recorded, of which $22.44 \%$ were to the knee, followed by $18.3 \%$ to the leg. In the upper extremities, the shoulder was most frequently affected $(11.8 \%)$.

By location, the knee was most commonly affected in both men and women $(23.1 \%$ and $20.8 \%$, respectively), but the shoulder

\section{Table 1}

Characteristics of the sample, by gender.

\begin{tabular}{|c|c|c|c|c|c|c|c|c|c|c|c|c|c|}
\hline \multirow[b]{3}{*}{ Age } & \multirow{3}{*}{$\begin{array}{l}\text { Mean } \\
50.60\end{array}$} & \multirow{3}{*}{$\begin{array}{c}\text { SD } \\
11.41\end{array}$} & \multicolumn{2}{|c|}{$95 \% \mathrm{CI}$} & \multirow{3}{*}{$\begin{array}{l}\text { Mean } \\
50.18\end{array}$} & \multirow{3}{*}{$\begin{array}{c}\text { SD } \\
10.72\end{array}$} & \multicolumn{2}{|c|}{$95 \% \mathrm{CI}$} & \multirow{3}{*}{$\begin{array}{l}\text { Mean } \\
51.58\end{array}$} & \multirow{3}{*}{\begin{tabular}{c}
\multicolumn{1}{c}{ SD } \\
Fer \\
12.95
\end{tabular}} & \multicolumn{2}{|c|}{$95 \% \mathrm{CI}$} & \multirow{3}{*}{$\frac{\boldsymbol{P} \text {-value }}{.49}$} \\
\hline & & & \multicolumn{2}{|c|}{ tal } & & & \multicolumn{2}{|c|}{ ale } & & & \multicolumn{2}{|c|}{ nale } & \\
\hline & & & 48.76 & 52.44 & & & 48.11 & 52.26 & & & 47.69 & 55.47 & \\
\hline Height & 173.52 & 9.48 & 171.99 & 175.05 & 177.29 & 6.81 & 175.97 & 178.60 & 164.73 & 9.04 & 162.02 & 167.45 & .00 \\
\hline BMl & 25.03 & 3.60 & 24.45 & 25.61 & 25.56 & 3.36 & 24.91 & 26.21 & 23.78 & 3.87 & 22.62 & 24.94 & .01 \\
\hline Years' experience & 27.20 & 14.40 & 24.88 & 29.52 & 26.73 & 14.51 & 23.92 & 29.54 & 28.29 & 14.22 & 24.02 & 32.56 & .55 \\
\hline Hours' training per week & 5.07 & 3.33 & 4.54 & 5.61 & 5.11 & 3.44 & 4.45 & 5.78 & 4.98 & 3.10 & 4.05 & 5.91 & .82 \\
\hline
\end{tabular}

$\mathrm{Cl}=$ confidence interval; $\mathrm{SD}=$ standard deviation. 


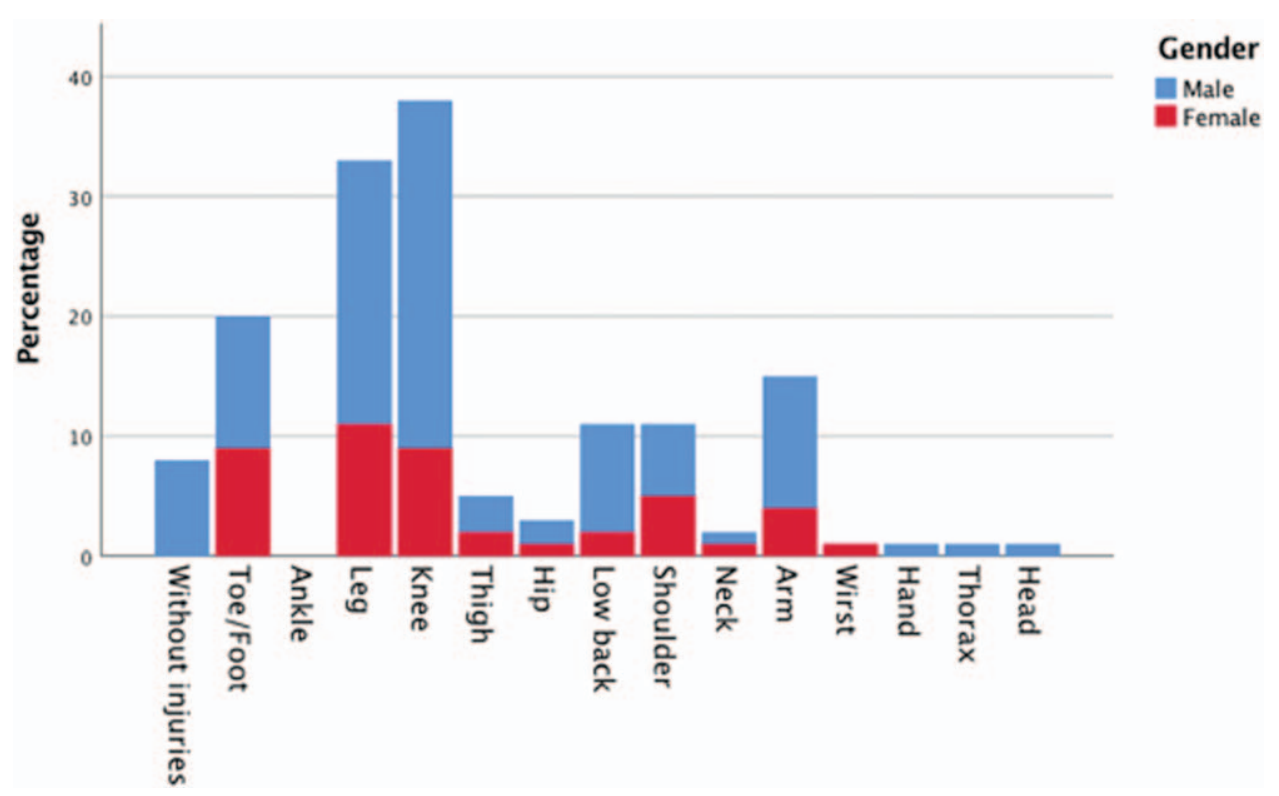

Figure 1. Bar graph location of injuries by sex.

was affected more frequently among women than men $(17.8 \%)$ (Fig. 1).

The severity of the injuries was greater among the knee, which accounted for $35 \%$ of the severe injuries. Significant differences were observed in the type and location of injury $(P<.001)$ (Table 2).

By type of injury, those to the muscles ( $n=126,39.1 \%$ ) were the most common, followed by ligament injuries, sprains, and damage to the tendons $(n=99,30.9 \%)$. (Fig. 2).

A multivariate linear regression model was constructed, with total injuries per 1000 hours of training as the dependent variable and years of badminton experience, sex, weekly hours' training, location of skeletal muscle injuries, type of injury, and age as predictors. This regression produced a model with a predictive capacity of $44 \%$. The only significant factor was that experience, which was inversely related with total injuries per 1000 hours of training (Table 3).

\section{Discussion}

Only limited data are available on the incidence and characteristics of injuries to badminton players. To our knowledge, the present study is the first in nearly 20 years to analyze the location, type, and mechanism of injury in amateur badminton

\section{Table 2}

Location of injuries, according to severity.

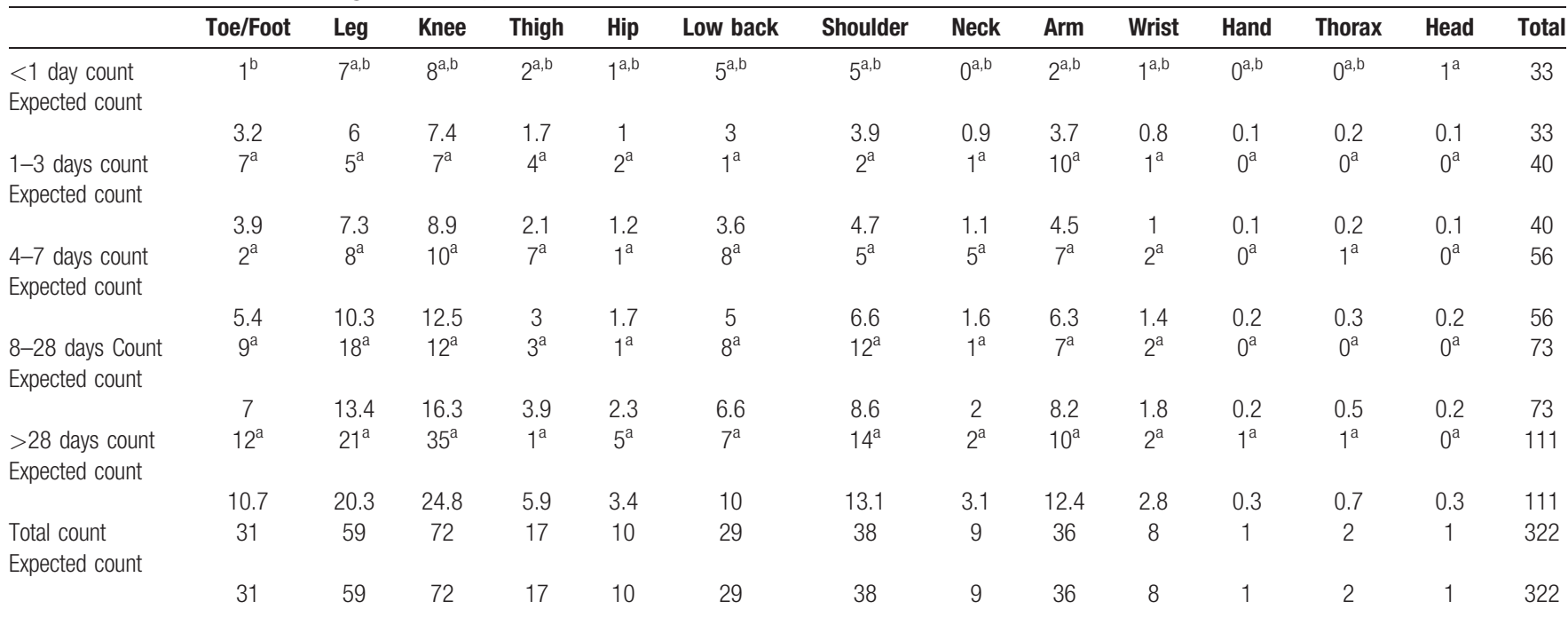

The expected minimum count is 0 .

${ }^{a} P<.01$ cells $(72.6 \%)$ have expected a count $<5$.

${ }^{\mathrm{b}} \mathrm{P}<.0561$ cells $(72.6 \%)$ have expected a count $<5$. 


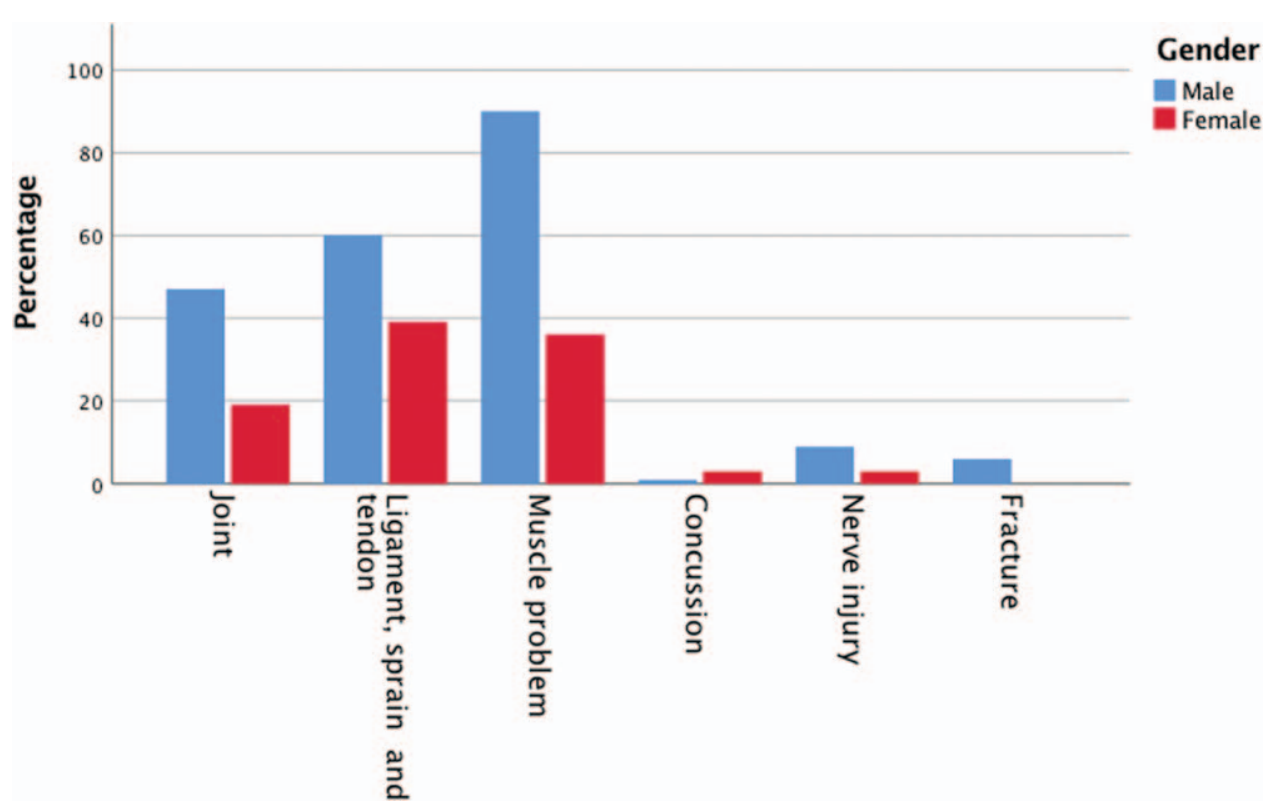

Figure 2. Bar graph type of injuries by sex.

players. ${ }^{[9,15]}$ The association between injuries and performance is probably one of the most important messages to convey to medical, technical, and coaching staff, as well as to other stakeholders, in order to improve medical services for the players and to prevent injuries.

In our study, a total of 322 injury records were generated by 150 players. By injury location, $22.44 \%$ of the injuries were to the knee, followed by $18.3 \%$ to the leg. In the upper limbs, the shoulder was most frequently affected $(11.8 \%)$. In this respect, Krøner et $\mathrm{al}^{[15]}$ reported that $82.9 \%$ of injuries affected the lower extremities, and Jorgensen and Winge ${ }^{[7]}$ recorded $58 \%$ of lower limb injuries. Upper extremity injuries were also present, this being a particular feature of racket sports. ${ }^{[16]}$ Other types of injury that have been reported in previous research include Achilles tendon rupture, ${ }^{[2]}$ ankle ligamentous sprain, ${ }^{[6]}$ ankle fracture, ${ }^{[5]}$ eye trauma, ${ }^{[17]}$ shoulder impingement, ${ }^{[18]}$ shoulder dislocation, ${ }^{[19]}$ wrist injury, ${ }^{[20]}$ tennis elbow, ${ }^{[7]}$ and muscle cramps, blisters, and strains. ${ }^{[21]}$ Epidemiological studies have shown that among badminton players the areas most commonly affected by injury are the ankle $(23.5 \%)$, knee $(14.0 \%)$, foot $(12.5 \%)$, arm $(8.5 \%)$, and leg $(5.4 \%) .{ }^{[1]}$ Injuries to the knee may be influenced by the footwear adopted. ${ }^{[22]}$ It should also be taken into account that impact forces and knee movements are of crucial importance in understanding the kinetic characteristics of the lower extremity during a lunge movement. ${ }^{[23]}$

\section{Table 3}

Multivariate model for total injuries.

\begin{tabular}{lccc}
\hline & Standardized beta & $\mathbf{9 5 \%} \mathbf{~ C l}$ & $\boldsymbol{P}$-value \\
\hline Age y & 0.095 & 0.648 to -0.052 & .180 \\
Gender (male/female) & 0.011 & -0.108 to 0.439 & .858 \\
Type of injury & 0.045 & -0.019 to 0.05 & .490 \\
Location of injury & 0.041 & 0.118 to -0.135 & .527 \\
Training, h & 0.659 & 0.079 to -0.135 & .000 \\
Experience, y & -0.128 & $1-0.069$ & .074 \\
\hline
\end{tabular}

In our sample, 2.07 of male and 1.99 of female players suffered an injury, figures similar to those reported by Jorgensen and Winge in $1987 .{ }^{[7]}$ However, among younger players the opposite is true, with women suffering 3 times more injuries than men. ${ }^{[1]}$ The mean rate of injuries per 1000 hours of training was 0.13 (SD: 0.1), and the values were very similar for male and female players, at 0.138 (SD: 0.1) and 0.131 (SD: 0.08), respectively. In this case, however, our findings differ considerably from those reported previously. Thus, Goh et al ${ }^{[8]}$ reported mean values of 0.57 injuries per 1000 hours of training for men and 0.9 for women, although in this study the subjects were younger. Hensley and Paup ${ }^{[21]}$ reported the incidence in terms of injuries per year, with figures of 0.09 and 0.14 for male and female players, respectively. In this case, however, the time period considered was the playing season and not per 1000 hours of training/playing. According to Jorgensen and Winge, ${ }^{[7]}$ the injury rate was found to be higher in training than in competition, which was in contrast to most other published sports data (in our case, this information was not reported).

The players in our sample lost an average of 14.93 days playing time per injury suffered, which is comparable with previous reported values. Thus, Fahlström et al, ${ }^{[6]}$ reported that $51.3 \%$ of badminton injuries were minor and $48.7 \%$ were moderate, while Høy et $\mathrm{al}^{[5]}$ reported that $17 \%$ were minor, $56 \%$ were moderate, and $27 \%$ were severe.

By type of injury, the largest group was that of muscle injuries, which is in line with the findings of Jorgensen and Winge, ${ }^{[7]}$ Krøner et al, ${ }^{[15]}$ and Høy et al, ${ }^{[5]}$ although it contrasts with Goh et $a 1,{ }^{[8]}$ who studied younger players.

Today's badminton is faster, more athletic, more physical, more prone to injury, more focused on tactics, less tolerant of unfair play, better equipped, and more professional, than that of 50 years ago. Accordingly, training programmes must be improved to adapt players to the current demands made in this sport, taking care not to focus exclusively on physiological aspects and physical fitness, despite the essential presence of these qualities in badminton. ${ }^{[24]}$ 
Badminton players should seek to protect the knee in particular, which is the body location most subject to injury, by forcefully extending the knee with internal rotation, strengthening the muscles around the ankle ligament, and maximizing joint coordination during training. ${ }^{[25]}$

A limitation of our study is that it did not include exposure time during competition. However, badminton is not played with a time limit. A match can last from 20 to 90 minutes and therefore including exposure time during competition would be highly complex, and beyond our limited resources.

\section{Conclusions}

Our study findings reveal differences in the incidence of injury according to the players' sex and age. By type of injury, those to the muscles are the most frequent, and by location, those to the knee (in the lower limb) and the shoulder (in the upper limb).

Older players, those who are female and those who dedicate more hours to training are all more likely to suffer injury, while greater experience is a protective factor.

\section{Author contributions}

Conceptualization: Gabriel Gijon-Nogueron, David CabelloManrique, Ana Belen Ortega-Avila.

Data curation: Ana Marchena-Rodriguez.

Formal analysis: Gabriel Gijon-Nogueron, David CabelloManrique.

Methodology: Gabriel Gijon-Nogueron, Ana Belen OrtegaAvila.

Writing - original draft: Gabriel Gijon-Nogueron, David Cabello-Manrique

Writing - review \& editing: Gabriel Gijon-Nogueron, David Cabello-Manrique, Ana Marchena-Rodriguez, Ana Belen Ortega-Avila.

\section{References}

[1] Yung PSH, Chan RHK, Wong FCY, et al. Epidemiology of injuries in Hong Kong elite badminton athletes. Res Sport Med 2007;15:133-46.

[2] Fahlström M, Lorentzon R, Alfredson H. Painful conditions in the Achilles tendon region in elite badminton players. Am J Sports Med 2002;30:51-4.

[3] Fahlström M, Yeap JS, Alfredson H, et al. Shoulder pain - A common problem in world-class badminton players. Scand J Med Sci Sport 2006; $16: 168-73$.
[4] Park SK, Lam WK, Yoon S, et al. Effects of forefoot bending stiffness of badminton shoes on agility, comfort perception and lower leg kinematics during typical badminton movements. Sport Biomech 2017; 16:374-86.

[5] Høy K, Lindblad BE, Terkelsen CJ, et al. Badminton injuries-a prospective epidemiological and socioeconomic study. Br J Sports Med 1994;28:276-9.

[6] Fahlström M, Björnstig U, Lorentzon R. Acute badminton injuries. Scand J Med Sci Sports 1998;8:145-8.

[7] Jorgensen U, Winge S. Epidemiology of badminton injuries. Int J Sports Med 1987;8:379-82.

[8] Goh SL, Mokhtar AH, Mohamad Ali MR. Badminton injuries in youth competitive players. J Sports Med Phys Fitness 2013;53:65-70.

[9] Jorgensen U, Winge S. Injuries in badminton. Sport Med 1990;10:59-64.

[10] Weir MA, Watson AWS. A twelve month study of sports injuries in one Irish school. Ir J Med Sci 1996;165:165-9.

[11] Miyake E, Yatsunami M, Kurabayashi J, et al. A prospective epidemiological study of injuries in Japanese national tournament-level badminton players from junior high school to university. Asian J Sports Med 2016;7:5-10.

[12] Faude O, Meyer T, Rosenberger F, et al. Physiological characteristics of badminton match play. Eur J Appl Physiol 2007;100:479-85.

[13] Chang WD, Chang WY, Lee CL, et al. Validity and reliability of wii fit balance board for the assessment of balance of healthy young adults and the elderly. J Phys Ther Sci 2013;25:1251-3.

[14] Wong TKK, Ma AWW, Liu KPY, et al. Balance control, agility, eye-hand coordination, and sport performance of amateur badminton players: a cross-sectional study. Medicine (Baltimore) 2019;98:e14134.

[15] Krøner K, Schmidt SA, Nielsen AB, et al. Badminton injuries. Br J Sports Med 1990;24:169-72.

[16] Science AL. The major racket sports: a review [Internet]. J Sports Sci 2003;21:707-32.

[17] Tsui E, Lo CC, Lazzaro DR. Ruptured globe from badminton racquet injury while wearing spectacles. Can J Ophthalmol 2017;52:625.

[18] Lo YPC, Hsu YCS, Chan KM. Epidemiology of shoulder impingement in upper arm sports events. Br J Sports Med 1990;24:173-7.

[19] Wan Hazmy CH, Parwathi A. Sports-related shoulder dislocations: a state-hospital experience. Med J Malaysia 2005;60(suppl):22-5.

[20] Rang BH, Zhang F, Yin WF. Investigation on relative factors of wrist and shoulder injuries in badminton sports. Chin J Clin Rehabil 2006; 10:41-3.

[21] Hensley LD, Paup DC. A survey of badminton injuries. Br J Sports Med 1979;13:156-60.

[22] Lam WK, Ryue J, Lee KK, et al. Does shoe heel design influence ground reaction forces and knee moments during maximum lunges in elite and intermediate badminton players? PLoS One 2017;12:1-3.

[23] Kuntze G, Mansfield N, Sellers W. A biomechanical analysis of common lunge tasks in badminton. J Sports Sci 2010;28:183-91.

[24] Huang H, Chatchawan U, Eungpinichpong W, et al. Progressive decrease in leg-power performance during a fatiguing badminton field test. J Phys Ther Sci 2019;31:765-70.

[25] Fu L, Ren F, Baker JS. Comparison of joint loading in badminton lunging between professional and amateur badminton players. Appl Bionics Biomech 2017;2017:1-8. 